By

Andrew McGettrick and Yan Timanovsky

\title{
DIGEST OF ACM EDUCATIONAL ACTIVITIES
}

W elcome to the third installment of EduBits, your quarterly pipeline to new and exciting happenings in the world of ACM education. Starting with this March issue of ACM Inroads, we are introducing a new thread that will highlight principal educational activities within ACM and affiliated organizations. Starting with this issue, you'll find a special focus on an ACM Special Interest Group (SIG) engaged in educational activities. News summaries will also include updates from task groups and committees of the ACM Education Council and within the institution itself.

This issue also features a status report from the CS2013 curricula revision task force and highlights of the many educational activities within SIGGRAPH, ACM's Special Interest Group on Computer Graphics and Interactive Techniques. In the spirit of community inclusiveness and broadening participation that permeates the Education Council, these pieces come straight from the people leading these important educational efforts. We trust you'll find their words informative and engaging and welcome your feedback. Enjoy.

We begin with a dedicated group of volunteers guiding a major revision of undergraduate computer science curricula recommendations: CS2013.

\section{The UK Royal Society Report: Shut Down or Restart? The Way Forward for Computing in UK Schools}

Computing in high schools (and in earlier education) has been a matter of considerable concern in many countries. Existing computing curricula have not been seen as attractive to many students and this has resulted in reduced enthusiasm to study the discipline at an advanced level and to see it as a basis for ongoing professional activity. The importance of computing to innovation and to wealth creation has had the effect of elevating this to crisis proportions.

In the UK these matters had culminated in the UK Royal Society undertaking a study into computing in schools (in the UK this should be interpreted as high schools). This work was done in cooperation with the Royal Academy of Engineering, the British Computer Society (BCS), and the Council of Professors of Computer Science. Industry and the relevant UK research council sponsored the effort. Professor Steve Furber of Manchester University chaired the study. The eighteen-month study began in August of 2010; the final report was published in January of 2012.

The report does not address directly the issue of curricula; however, it recognizes that further work is needed to produce new curricula to enthuse students. Its eleven recommendations tend to focus on such matters as: abandoning the term ICT (information

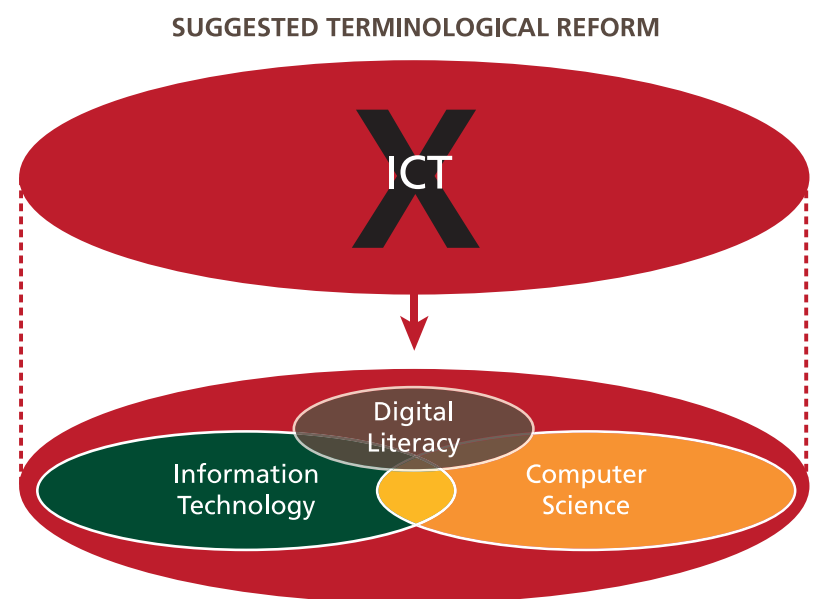


and communications technology) due to its negative overtones in the UK and replacing this with a focus on the three concepts of digital literacy, ${ }_{1}^{1}$ information technology, ${ }^{2}$ and computer science, ${ }^{3}$ which are defined in the report; promoting computer science as a rigorous academic discipline; addressing the important matter of teachers and the continuing professional development of teachers; seeking ways of extending available resources to support computing education; ensuring that all children have appropriate opportunities to study computing; and, seeking support from the government to monitor the general situation so that improvement is guaranteed. Finally, the report recommends the establishment of a "UK Forum for joint working and coordination between the many computing bodies, in order to progress the recommendations within this report".

In short the report has to be seen as a starting point for further work. The full report is available at http://royalsociety.org/education/policy/ computing-in-schools/report/ .

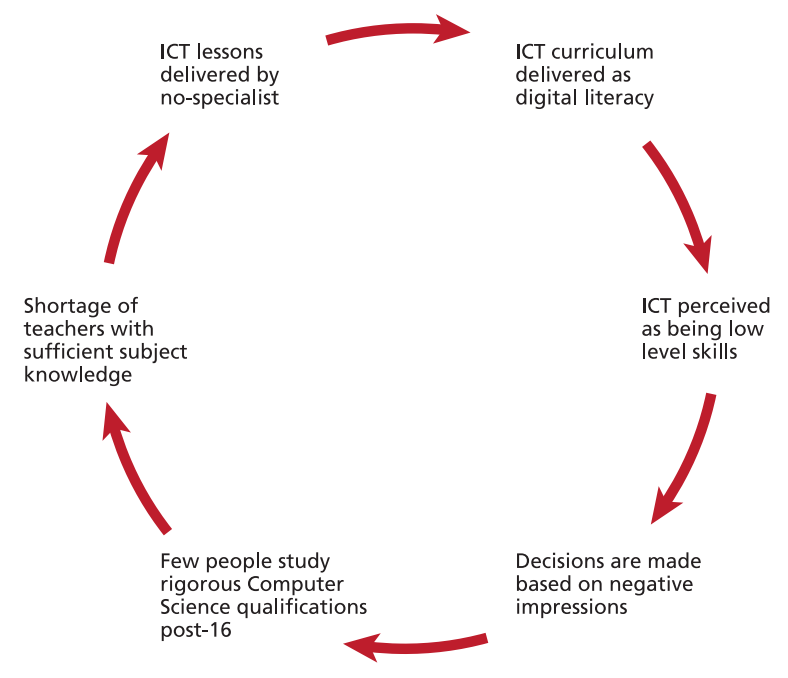

\section{Education on Human-Computer Interaction}

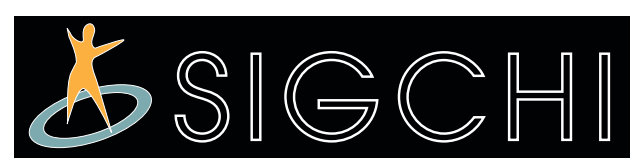

ACM's Special Interest Group on Computer-Human Interaction (SIGCHI) has been active for thirty years. The first conference on "Human Factors in Computer Systems" was held in 1982 in Gaithersburg, Maryland. This conference in fact triggered the founding of SIGCHI, the worldwide, largest truly international association of professionals in human-computer interaction. The CHI Conference, as it is now known, annually draws between 2600 and 3000 attendees from over the world. The conference itself travels between North America and Europe; in 2015 it will host the largest SIGCHI event for the first time in South-East Asia. Besides CHI and about fifteen SIGCHI-sponsored events, and over twenty "in cooperation" specialized conferences in the field, SIGCHI focuses on developing the field. Furthermore, over all these conferences, about $40 \%$ of the attendees are students.

Obviously, education is one of the focal points. Students pay a low membership fee and conference fees that are below actual costs. SIGCHI has contributed to education curricula, including the ACM-IEEE documents. In $\sim$ 1992, SIGCHI published a complete HCI Education curriculum. Before long we found out that the computer side of $\mathrm{HCl}$ developed too quickly to predict educational needs long in advance. Moreover, education differs strongly in different parts of the world, and it often develops into new directions. For example, the European national education models changed drastically as a result of the Bologna treaty in 1999.

Recently, SIGCHI started a research project to better understand the current state of academic and practitioner education. Project leaders Elizabeth Churchill, Jenny Preece, and Anne Bowser recently produced their first report,

1 Defined in the report as "The general ability to use computers"

2 Defined in the report as "The general ability to use computers"

$\frac{\underline{v}}{x} 3$ "The use of computers, in industry, commerce, the arts and elsewhere, including aspects of IT systems architecture, human factors, project management, etc." 


\section{Digest of ACM Educational Activities}

which followed a pilot survey with over 170 respondents and more than 50 follow-up interviews, close to 300 participants worldwide answered an extended questionnaire on central topics, emerging trends, and critical challenges. Of these, $48 \%$ identified themselves as academic, $38 \%$ as industry professional, and $28 \%$ as students (some choose multiple labels).

Crucial topics in $\mathrm{HCl}$ education were, first of all, related to design and research methodologies: qualitative as well as quantitative research, observation and interview techniques, and empirical research methods. Specific techniques mentioned were mainly related to prototyping, including paper- and low-fidelity prototypes.

Many respondents indicated that they do not believe that subjects and topics in $\mathrm{HCl}$ should be common focal points in $\mathrm{HCl}$ education; subjects and application areas should reflect individual interests and areas of expertise. Regarding the foundations of $\mathrm{HCl}$ in computer science, psychology, and design, the respondents recommended emphasizing methods and practical knowledge over a deep knowledge of topics. These results show us clearly that a detailed unified $\mathrm{HCl}$ curriculum does not fit the current landscape of educational structures and industrial needs.

Our membership and our conference attendance closely match the survey sample distribution of academics, practitioners, and students. Our students generally observe that the current $\mathrm{HCl}$ education seems to prepare them well for academia but less for an industry career, where practitioners emphasize the importance of practice (design studio and internships) and stress the need for education to focus on how business professionals communicate. Overall, all groups noted that it was important to discourage students from becoming a "jack of all trades, master of none." Gaining knowledge in one special domain, on the other hand (e.g., healthcare, banking, or e-government) was advised. Both academics and industry professionals mentioned the need to collaborate systematically in education between these two sub-disciplines.

SIGCHI's education project continues. We will be looking into international differences, into needs for support and guidelines at various education levels as well as for various geographical areas, and we will continue to investigate the mismatch between what is taught and what is experienced in professional life.

Gerrit C. van der Veer SIGCHI President

Finally, we go behind the scenes of Washington, D.C. and get an introduction to ACM's efforts in education policy with ACM Director of Public Policy Cameron Wilson.

\section{ACM's Engagement in Public Policy}

Many of today's major societal issues involve understanding increasingly complex scientific and technical matters and how these impact the public, practitioners, and policymakers. As the world's oldest, largest, and most respected society of computer and technology professionals, ACM is uniquely positioned to offer outstanding leadership to educate and inform policymakers on the spectrum of issues within the computing community and to promote better public policy.

ACM pursues this mission through the U.S. Public Policy Council (USACM) and the Education Policy Committee (EPC). Both efforts rely on volunteers from the ACM community, the benefit of collective efforts, interdisciplinary expertise, and brainpower to address a portfolio of public policy issues in a nonpartisan manner and being consistent with the ACM Code of Ethics and Professional Conduct. 
The ACM U.S. Public Policy Council (USACM) is chartered to address U.S. public policy issues. The staff and members respond to inquiries from Congress and federal agencies for information and technical advice. USACM helps policymakers by reviewing proposed legislation and regulations, testifying at Congressional and regulatory hearings, providing reports and white papers, and convening programs that inform members about forthcoming government initiatives and actions. Six committees address accessibility, data privacy and security, digital government, intellectual property, tech policy law, and e-voting. USACM keeps members and the public informed about its activities and forthcoming opportunities through its website and blog (usacm.acm.org). USACM is open to U.S.-based ACM members in good standing.

Our engagement through ACM's Education Policy Committee is more closely aligned with the readers of ACM Inroads. The EPC (http://www.acm.org/public-policy/education-policy-committee) engages policymakers, academics, professionals, and the community in the exchange of ideas on public policy issues related to computer science education. EPC members assist policymakers by reviewing issues, commenting on proposals, providing reports, and meeting with government policymakers to raise awareness of computer science education issues. It has two basic strategic goals:

- Surfacing the computer science education issues within policy debates around education reform

- Ensuring that computer science courses "count" at the K-12 level toward a student's core credits

EPC's major accomplishments include the 2009 endorsement by the U.S. House of Representatives of Computer Science Education Week (CSEdWeek), the 2010 report "Running on Empty: The Failure to Teach K-12 Computer Science in the Digital Age," the 2011 congressional testimonies of EPC members Bobby Schnabel, Chris Stephenson, and Joanna Goode, and helping launch the Computing in the Core Coalition (www.computinginthecore.org), which is a multi-stakeholder coalition focused on advocating for $\mathrm{K}-12$ computer science education.

For 2012, EPC members will continue its work on strengthening policies around computer science education and are pursing two new areas of interest:

- educational pathways to the various employment opportunities in the computing and information technology fields, and

- comparative approaches to promote computer science within the career and technical education (CTE) curriculum

To learn more or to become involved, visit ACM's Public Policy Office online at: http://acm.org/public-policy.

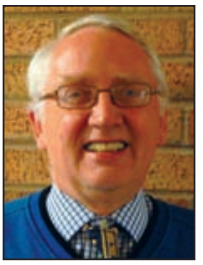

\section{ANDREW MCGETTRICK}

Chair, ACM Education Board

Professor of Computer Science,

Strathclyde University, Glasgow, UK

Andrew.McGettrick@cis.strath.ac.uk

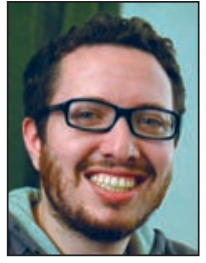

YAN TIMANOVSKY

Liaison to the Education Board

ACM Headquarters,

New York, New York USA

timanovsky@hq.acm.org 